\title{
One-stage posterior debridement and single-segment interbody fusion for treating mono-segmental lumbar and lumbosacral spinal tuberculosis in adults following minimum 5-year follow-up
}

Zhenchao $\mathrm{Xu}^{1,2}$, Xiyang Wang ${ }^{1,2^{*}}$ (D) and Zheng Liu ${ }^{1,2}$

\begin{abstract}
Background: To evaluate the mid-long-term outcomes of surgical management of mono-segmental lumbar and lumbosacral spinal tuberculosis (TB) in adults by one-stage posterior debridement, single-segment fixation, and titanium mesh cage interbody fusion.

Methods: A total of 62 patients with mono-segmental lumbar or lumbosacral spinal tuberculosis were enrolled. One-stage posterior debridement, single-segment fixation, and titanium mesh cage interbody fusion was performed. Clinical and radiographic outcomes were compared and analyzed.

Results: All patients were followed-up for an average of $75.0 \pm 11.5$ months and completely cured at the final follow-up. C-reactive protein (CRP) and erythrocyte sedimentation rate (ESR) returned to normal within three months postoperatively. Postoperative Japanese Orthopedic Association (JOA) score, visual analog scale (VAS) and Oswestry Disability index (ODI) were significantly improved compared with preoperative values. Bony fusion occurred after an average of $9.8 \pm 2.6$ months. The lordosis angle and lumbosacral angle were increased from preoperative $20.4 \pm 2.9^{\circ}$ and $14.7 \pm 3.4^{\circ}$ to postoperative $32.8 \pm 3.6^{\circ}$ and $22.4 \pm 5.5^{\circ}$, with angle loss of $1.0 \pm 0.7^{\circ}$ and $0.8 \pm 0.7^{\circ}$ at the final follow-up, respectively. No significant differences between preoperative and postoperative adjacent segment disc height $(\mathrm{DH})$ were found.

Conclusions: One-stage posterior debridement, single-segment fixation, and titanium mesh cage interbody fusion represent effective and feasible treatment option for mono-segmental lumbar and lumbosacral spinal tuberculosis in adults. This approach may preserve lumbar normal motor units and decrease adjacent segment degeneration (ASD) with the advantages of minimal invasiveness and rapid postoperative rehabilitation.
\end{abstract}

Keywords: Posterior debridement, Mono-segmental lumbar spinal tuberculosis, Mono-segmental lumbosacral spinal tuberculosis, Single-segment fixation

\footnotetext{
* Correspondence: wqlwqwxy@163.com

'Department of Spine Surgery and Orthopaedics, Xiangya Hospital, Central

South University, Changsha, China

${ }^{2}$ Hunan Engineering Laboratory of Advanced Artificial Osteo-Materials,

Central South University, Changsha, China
}

(c) The Author(s). 2020 Open Access This article is licensed under a Creative Commons Attribution 4.0 International License, which permits use, sharing, adaptation, distribution and reproduction in any medium or format, as long as you give appropriate credit to the original author(s) and the source, provide a link to the Creative Commons licence, and indicate if changes were made. The images or other third party material in this article are included in the article's Creative Commons licence, unless indicated otherwise in a credit line to the material. If material is not included in the article's Creative Commons licence and your intended use is not permitted by statutory regulation or exceeds the permitted use, you will need to obtain permission directly from the copyright holder. To view a copy of this licence, visit http://creativecommons.org/licenses/by/4.0/. The Creative Commons Public Domain Dedication waiver (http://creativecommons.org/publicdomain/zero/1.0/) applies to the data made available in this article, unless otherwise stated in a credit line to the data. 


\section{Background}

According to the global TB report in 2019 by World Health Organization, TB is the second most common fatal infectious diseases. There are more than 10 million new TB cases worldwide in 2019, causing approximately 1.2 million deaths [1]. As the most common extrapulmonary TB, spinal TB accounts for approximately $50 \%$ cases of skeletal TB [2]. With the increasing rate of HIV infection and TB drug-resistant strains, the prevalence of spinal TB has recently continued to rise. The lumbar and lumbosacral spine are sites most commonly affected by spinal TB. This severe disease is accompanied by a high refractory, disability, and recurrence rate, which seriously influences the quality of patients' life [3, 4].

Effective anti-TB drugs are still mainstay therapy for most patients with lumbar and lumbosacral spinal TB [5]. However, appropriate surgical treatment is the key to improve the cure rate. The aim of surgery is to remove lesions, improve neurological function and reconstruct spinal stability [6]. With the introduction of the spinal pedicle screw system, one-stage posterior approach has been increasingly adopted to treat lumbar and lumbosacral spinal TB by surgeons [7-9]. The rigid internal fixation system is able to prevent kyphosis progression and severe back pain caused by spinal instability. For the treatment of mono-segmental lumbar and lumbosacral spinal TB in adults, fixation including one or more normal motor units can be performed via posterior decompression and instrumentation. Although this procedure provides firm temporary stability, it also limits the activity of normal spinal motor unit and accelerates the degeneration of adjacent vertebral body [10-12]. Therefore, selection of appropriate fixed segment will determine the mid-long-term effect. In this study, we evaluated the effect of surgical treatment of mono-segmental lumbar and lumbosacral spinal TB in adults with one-stage posterior debridement, singlesegment fixation, and titanium mesh cage interbody fusion after at least 5 years of follow-up.

\section{Methods}

\section{Basic information}

This study enrolled 62 patients with mono-segmental lumbar and lumbosacral spinal TB, who were treated by one-stage posterior debridement, single-segment fixation, and titanium mesh cage interbody fusion between January 2010 and December 2014. The inclusion criteria were as follows: (1) the lesion mainly involved a functional unit of the lumbar and lumbosacral spine (L2-S1); (2) vertebral body damage was less than $1 / 2$ of the vertebral height so that the pedicle screw can be implanted; and (3) the paravertebral abscesses were limited to the diseased vertebrae. The exclusion criteria were as follows: (1) severe kyphosis caused by vertebral bone destruction; (2) severe osteoporosis in senile patients; (3) bone healing after tuberculous spondylitis with associated kyphosis deformity; and (4) huge paravertebral abscess or psoas abscess. The initial diagnosis of spinal TB was made based on the clinical presentations, hematologic examinations, and imaging findings, and the final diagnosis was made based on the pathological examination and tubercle bacillus culture. Patients who met the inclusion criteria were followed up for at least 5 years.

The demographic data and disease characteristics of patients are summarized in Table 1. All patients presented with constitutional symptoms such as night sweats, anorexia, weight loss, fatigue, and low back pain. Some patients also had symptoms of neurological impairment including sensory impairment and muscular weakness. All patients had elevated ESR and CRP values. Pain severity was assessed by VAS. The JOA and ODI were used to evaluate neurological function and the quality of life, respectively.

All patients underwent routine imaging examinations. Plain radiograph, computed tomography (CT), and magnetic resonance imaging (MRI) were used to detect vertebral body collapse, spinal instability, bone destruction, epidural and paravertebral abscess formation, and narrowing of the intervertebral space. Lesions with segments L2/3 L3/4, L4/5, and L5/S1 occurred in 11 cases, 17 cases, 21 cases, and 13 cases, respectively. The University of California at Los Angeles (UCLA) grading scale [13] was applied to assess the ASD on radiograph.

\section{Preoperative procedure}

All patients were treated with anti-TB drugs for 2 to 4 weeks prior to surgery, including isoniazid (300 $\mathrm{mg} /$ day), rifampicin (450 $\mathrm{mg} /$ day), and pyrazinamide $(750 \mathrm{mg} /$ day), and ethambutol (750 mg/day). Preoperative examinations were performed to exclude contraindications. Anemia and hypoproteinemia were corrected preoperatively, the targets for blood pressure and random blood glucose were below 140/90 $\mathrm{mmHg}$ and lower than 10.0 $\mathrm{mmol} / \mathrm{L}$, respectively. Surgery was performed when the ESR value returned to normal or had significantly decreased. Patients with progressive radiculopathy or cauda equine syndrome were treated with adequate anti-TB drugs. If the patients had no absolute contraindications, surgery was performed as soon as possible.

Table 1 Patient demographics and disease characteristics

\begin{tabular}{|c|c|c|c|c|}
\hline \multirow{2}{*}{$\begin{array}{l}\text { Number } \\
\text { of } \\
\text { patients }\end{array}$} & \multicolumn{2}{|c|}{ Gender } & \multirow{2}{*}{$\begin{array}{l}\text { Age } \\
\text { (years) }\end{array}$} & \multirow{2}{*}{$\begin{array}{l}\text { During of } \\
\text { symptoms } \\
\text { (months) }\end{array}$} \\
\hline & Male & Female & & \\
\hline 62 & 33 & 29 & $47.5 \pm 14.0$ & $3.1 \pm 1.3$ \\
\hline
\end{tabular}




\section{Operation procedure}

The patients were placed in a prone position under general endotracheal anesthesia. A posterior midline incision was made over the diseased vertebra, and the spinous processes, lamina, facet joints, and transverse processes were exposed. With the assistance of $\mathrm{C}$-arm fluoroscopy, pedicle screws were implanted in the affected vertebrae close to the endplates in order to preserve enough debridement space. A temporary rod was stabilized on the side of less bone destruction or neurologic manifestation to avoid nerve injury during focal debridement. Then, hemilaminectomy or laminectomy was performed on the severely damaged side of the lesion segment to expose the diseased vertebral bodies. Curettes of varying angles were used to remove the lesion focus, including sequestrum, necrotic intervertebral disc, tuberculous granuloma, and caseous necrosis. Pus and necrotic tissue were eliminated by negative pressure washing via a soft silicone tube which was placed deep into the lesion. The same procedure was performed on the other side, if necessary. The bone surfaces of the vertebral body were repaired as bone graft beds, and autogenous bone particles from healthy lamina and spinous process packed in one or two shaped titanium mesh cages were implanted into the front $2 / 3$ of the intervertebral to reconstruct the anterior middle column. Then, the opposite rod was installed, and compression was carried out after placement of interbody titanium mesh. Streptomycin $(0.1 \mathrm{~g})$ and isoniazid $(0.3 \mathrm{~g})$ were applied locally in the focus area, and the incision was closed in layers after a drainage tube was placed. The specimens were collected for mycobacterium culture and histopathological examination.

\section{Postoperative procedure}

Routine antibiotics were used to prevent infection. All patients received nutritional improvement and support treatment. Wound dressings were changed regularly, and the drainage tube was removed when the volume of drainage was less than $20 \mathrm{ml}$ in $24 \mathrm{~h}$. The patients continued with the anti-TB treatment regimen for 12 to 18 months. Routine blood test, liver function test, ESR and CRP were performed to monitor adverse reactions and to evaluate drug efficacy. After strict bed rest for 4 weeks, the patients gradually began to walk with the help of external braces for 3 months. Clinical and radiologic examinations were performed every 3 months in the first year after surgery and then every 6 months thereafter.

\section{Follow-up evaluation}

Lumbar anterolateral radiograph and CT were performed to assess the placement of graft and internal fixation. CT was used to evaluate bone healing according to the radiologic criteria by Lee et al. [14]. The following indexes were recorded preoperatively, postoperatively, and during the follow-up: (1) ESR and CRP; (2) neurological status according to JOA; (3) ODI and VAS; (4) adjacent segment (DH); and (5) lordosis angle and lumbosacral angle.

\section{Statistical analysis}

Statistical analyses were performed using the SPSS 20.0 software. The clinical and radiographic data between preoperative and postoperative were compared using paired $t$ test. Discrepancy of the normal distribution was evaluated using the rank sum test. $P$ value of less than 0.05 was considered statistically significant.

\section{Results}

\section{Clinical outcomes}

Tuberculous granulomas or caseous necrosis was confirmed by pathological examination of the surgical specimens. The average follow-up time was $75.0 \pm 11.5$ months. All patients were diagnosed with lumbar or lumbosacral spinal TB and achieved clinically cure. Preoperative CRP and ESR were $43.5 \pm 14.9 \mathrm{mg} / \mathrm{L}$ and 69.1 $\pm 17.8 \mathrm{~mm} / \mathrm{h}$, respectively. The values returned to normal at three months postoperatively. For patients with preoperative neurological dysfunction, neurological function improved to varying degrees after surgery. The JOA improved from preoperative $18.3 \pm 3.7$ to $26.9 \pm$ 2.2 at the final follow-up $(P<0.05)$. The VAS and ODI values were $6.9 \pm 1.1$ and $42.6 \pm 6.2$ preoperatively and significantly decreased to $1.0 \pm 0.8$ and $10.2 \pm 1.6$ at the last follow-up, respectively, $(P<0.05)$ (Table 2).

\section{Radiographic outcomes}

The lordosis angle and lumbosacral angle increased from preoperative $20.4 \pm 2.9^{\circ}$ and $14.7 \pm 3.4^{\circ}$ to $32.8 \pm 3.6^{\circ}$ and $22.4 \pm 5.5^{\circ}$ immediately postoperative, resulting in angle loss of $1.0 \pm 0.7^{\circ}$ and $0.8 \pm 0.7^{\circ}$ at the final follow-up, respectively. The lordosis angle or lumbosacral angle was significantly improved immediately postoperative and at the last visit, compared with preoperatively measurements $(P<0.05)$. The mean fusion time was $9.8 \pm 2.6$ months (Table 3). There was no significant difference between preoperative and postoperative adjacent segment $\mathrm{DH}$ (Table 4). According to the UCLA grading scale, 52 patients had grade I ASD and 10 patients had grade II ASD preoperatively. At the final follow-up, 8 patients progressed from grade I ASD to grade II ASD, and 2 patients from grade II ASD to grade III ASD. The average rates of titanium mesh cage subsidence measured at the site of bone graft fusion were $0.8 \pm 0.2 \mathrm{~mm}, 0.9 \pm 0.1 \mathrm{~mm}, 1.2 \pm$ $0.2 \mathrm{~mm}$, and $1.1 \pm 0.2 \mathrm{~mm}$ in patients with segments $\mathrm{L} 2 / 3$ $\mathrm{L} 3 / 4, \mathrm{~L} 4 / 5$, and L5/S1, respectively. All patients achieved satisfactory bone graft fusion. No non-union, pseudoarthrosis, loosening or fracture of instruments occurred at the last visit (Figs. 1 and 2). 
Table 2 Clinical outcomes of patients

\begin{tabular}{|c|c|c|c|c|c|c|c|c|c|c|c|c|}
\hline \multicolumn{3}{|c|}{ CRP (mg/L) } & \multicolumn{3}{|c|}{$\operatorname{ESR}(\mathrm{mm} / \mathrm{h})$} & \multicolumn{2}{|l|}{ JOA } & \multicolumn{2}{|l|}{ VAS } & \multicolumn{2}{|l|}{ ODI } & \multirow{2}{*}{$\begin{array}{l}\text { Follow-up } \\
\text { (months) }\end{array}$} \\
\hline Pre & TMP & FFU & Pre & TMP & FFU & Pre & FFU & Pre & FFU & Pre & FFU & \\
\hline $\begin{array}{l}43.5 \pm \\
14.9\end{array}$ & $\begin{array}{l}4.4 \pm \\
1.2^{*}\end{array}$ & $\begin{array}{l}2.0 \pm \\
0.6^{*}\end{array}$ & $\begin{array}{l}69.1 \pm \\
17.8\end{array}$ & $\begin{array}{l}12.0 \pm \\
3.1^{*}\end{array}$ & $\begin{array}{l}4.5 \pm \\
1.7^{*}\end{array}$ & $\begin{array}{l}18.3 \pm \\
3.7\end{array}$ & $\begin{array}{l}26.9 \pm \\
2.2^{*}\end{array}$ & $\begin{array}{l}6.9 \pm \\
1.1\end{array}$ & $\begin{array}{l}1.0 \pm \\
0.8^{*}\end{array}$ & $\begin{array}{l}42.6 \pm \\
6.2\end{array}$ & $\begin{array}{l}10.2 \pm \\
1.6^{*}\end{array}$ & $\begin{array}{l}75.0 \pm \\
11.5\end{array}$ \\
\hline
\end{tabular}

Pre preoperative, TMP three months postoperative, FFU final follow-up

${ }^{*}$ Analyzed by paired $t$ test, compared with preoperatively, $P<0.05$

\section{Complications}

Superficial wound infection occurred in nine patients including 2 patients with Staphylococcus aureus, 1 patient with $E$. coli, and the 6 patients with negative bacterial culture results. The infection was cured by antibiotics. Four patients experienced hypostatic pneumonia and were treated with sensitive antibiotics according to the results of sputum culture. Local abscess recurrence due to irregular administration of anti-TB drugs occurred in one patient, who was treated by catheter drainage through minimally invasive incision and regular chemotherapy. No operative mortality or permanent nerve injury occurred.

\section{Discussion}

The local anatomical structures of the lumbar region are complex and adjacent to many vital organs. Lumbar stability is maintained by the combined effects of the vertebrae, intervertebral discs, muscle groups, and ligaments in the face of strong pressure and shear stress. Among all spinal regions, lumbar and lumbosacral segments subject to the largest load and exhibit the greatest mobility. Lumbar and lumbosacral spinal TB has the characteristics of insidious onset and atypical symptoms at early stages. Patients often present with low back pain and are easily misdiagnosed with degenerative spinal diseases such as lumbar disc herniation, lumbar spinal stenosis and osteoporosis [15]. With progression of the disease, sequestrum and abscesses can lead to vertebral collapse, spinal instability, kyphosis deformity, and changes in normal physiological curvature and load biomechanics, or invade the spinal canal to compress the nerves, resulting in nerve damage or even paralysis [16].

There are many surgical approaches for treating lumbar and lumbosacral spinal TB [17-20]. The posterior approach is associated with some advantages such as lesion removal, and simultaneous intervertebral bone graft and fixation through one incision without position changing. Additionally, pedicle screws can effectively correct the kyphosis via the posterior approach, thus restoring the normal physiological lordosis of the lumbar segment. Furthermore, the posterior approach is less invasive and avoids possible damage to the large vessels, nerves, or vital anatomical structures. Therefore, many surgeons recommend posterior-only approach for lumbar and lumbosacral spinal TB, which achieves good curative effects [7-9, 20]. The rationale behind the posterior approach is removal of the sequestrum that prevents anti-TB drugs from entering the lesions. The small amount of residual lesions and abscesses can be absorbed following postoperative standardized anti-TB chemotherapy.

Previous studies have shown that the range of fixation for mono-segmental lumbar and lumbosacral spinal TB in adults involves one to multiple normal motion units above and below the lesion via posterior debridement, decompression, and instrumentation. Although multi-segment fixation provides strong temporary stability, it sacrifices the motion of the fixed segments and accelerates degeneration of adjacent segments $[21,22]$. Since the lumbar region requires greater mobility than the rest of vertebral column, adopting a surgical approach with minimally invasion and less damage to vertebral function is the major goal for treating monosegmental lumbar and lumbosacral spinal TB. Previous studies have reported that the spinal motor unit remains essentially unchanged following single-segment fixation with pedicle screws in the treatment of spinal fractures. Spinal stability in patients with fractures of spine can be achieved by mono-segment fixation [23]. For the treatment of lumbar and lumbosacral spinal TB, single-segment fixation with pedicle screw is feasible because of the reactive new bone formation in vertebrae affected by TB. The involved vertebrae often presents with sclerotic bones, resulting in higher bone

Table 3 Radiographic outcomes of patients

\begin{tabular}{|c|c|c|c|c|c|c|c|c|c|c|}
\hline \multicolumn{5}{|c|}{ lordosis angle $\left({ }^{\circ}\right)$} & \multicolumn{5}{|c|}{ lumbosacral angle $\left(^{\circ}\right)$} & \multirow{2}{*}{$\begin{array}{l}\text { Fusion } \\
\text { time } \\
\text { (months) }\end{array}$} \\
\hline Pre & Post & FFU & $\begin{array}{l}\text { Angle } \\
\text { lost }\end{array}$ & $\begin{array}{l}\text { Correction rate } \\
\text { (\%) }\end{array}$ & Pre & Post & FFU & $\begin{array}{l}\text { Angle } \\
\text { lost }\end{array}$ & $\begin{array}{l}\text { Correction rate } \\
\text { (\%) }\end{array}$ & \\
\hline $\begin{array}{l}20.4 \pm \\
2.9\end{array}$ & $\begin{array}{l}32.8 \pm \\
3.6^{*}\end{array}$ & $\begin{array}{l}31.8 \pm \\
3.5^{*}\end{array}$ & $1.0 \pm 0.7$ & $37.8 \pm 4.5$ & $\begin{array}{l}14.7 \pm \\
3.4\end{array}$ & $\begin{array}{l}22.4 \pm \\
5.5^{*}\end{array}$ & $\begin{array}{l}21.5 \pm \\
5.0^{*}\end{array}$ & $0.8 \pm 0.7$ & $34.1 \pm 6.1$ & $9.8 \pm 2.6$ \\
\hline
\end{tabular}

Lordosis angle: 49 cases with a local lumbar lordosis angle in lesions

Lumbosacral angle: 13 cases with a local lumbosacral lordosis angle in lesions

Pre preoperative, Post postoperative immediately, FFU final follow-up

${ }^{*}$ Analyzed by paired $t$ test, compared with preoperatively, $P<0.05$ 
Table 4 The change of adjacent segment DH

\begin{tabular}{|c|c|c|c|c|c|c|c|c|}
\hline & \multicolumn{2}{|l|}{$L 2 / 3$} & \multicolumn{2}{|l|}{$L 3 / 4$} & \multicolumn{2}{|l|}{ L4/5 } & \multicolumn{2}{|l|}{$\mathrm{L} 5 / \mathrm{S} 1$} \\
\hline & Pre & FFU & Pre & FFU & Pre & FFU & Pre & FFU \\
\hline Upper DH (mm) & $8.8 \pm 0.4$ & $8.6 \pm 0.3$ & $8.6 \pm 0.4$ & $8.4 \pm 0.3$ & $10.3 \pm 0.6$ & $10.0 \pm 0.5$ & $11.1 \pm 0.5$ & $10.8 \pm 0.4$ \\
\hline Lower DH (mm) & $10.1 \pm 0.4$ & $9.8 \pm 0.4$ & $10.7 \pm 0.6$ & $10.6 \pm 0.6$ & $9.7 \pm 0.6$ & $9.5 \pm 0.5$ & / & / \\
\hline
\end{tabular}

Pre preoperative, FFU final follow-up

mineral density than normal vertebral body. This pathological process results in stronger holding forces for pedicle screws in the involved vertebrae, compared with fracture [24]. Liu et al. [25] compared the results of mono-segment fixation versus short-segment fixation for the treatment of single-segment lumbar spinal TB and found that monosegment fixation was more suitable since the normal motion was preserved. $\mathrm{Xu}$ et al. [26] reported that single-segment fixation and bone fusion was effective in maintaining the stability of the spine and retaining normal motion units. In the present study, the lordosis and lumbosacral angle increased from preoperative $20.4 \pm 2.9^{\circ}$ and $14.7 \pm 3.4^{\circ}$ to postoperative $32.8 \pm 3.6^{\circ}$ and $22.4 \pm 5.5$. Our findings suggest that deformity was effectively corrected. The characteristic of lumbar and lumbosacral lordosis and longitudinal arrangement of facet joints, which buffer the effect of kyphosis caused by bone destruction. Therefore, mono-segment fixation is sufficient for relatively small orthopedics. In addition, there was no significant difference between the preoperative and final adjacent segment $\mathrm{DH}$, and the ASD rate was lower in this study (16.1\%) than the incidence of ASD (range 21.3 to $31.9 \%)$ after lumbar fusion reported by the recent meta-
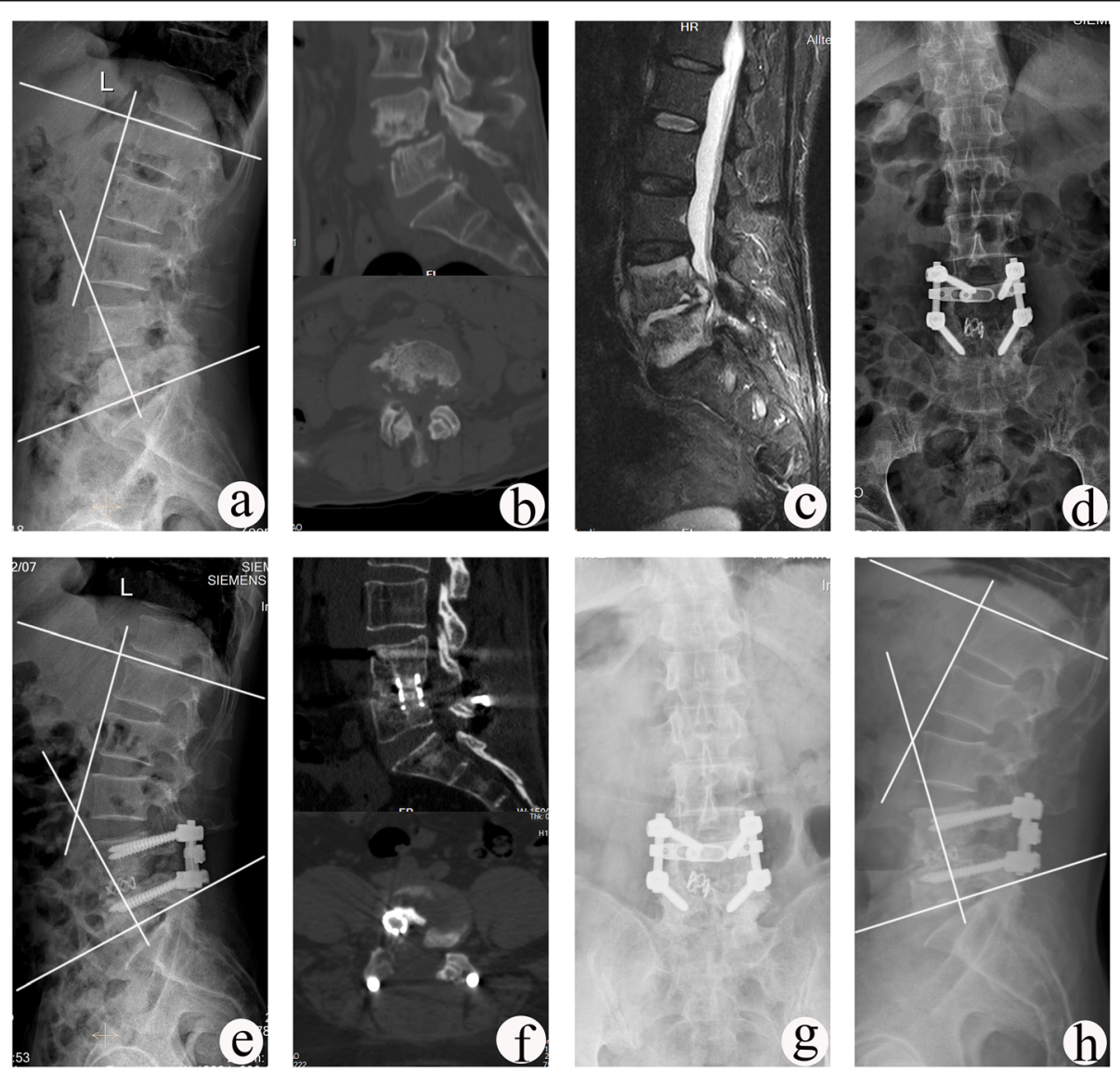

Fig. 1 A 61-year-old male with L4-L5 TB underwent one-stage posterior debridement, titanium mesh cage bone grafting and single-segment fixation. a-c Preoperative images showing that the lesion was located at $L 4-L 5$ with a lordosis angle of $26^{\circ}$. $\mathbf{d}$, e Postoperative $X$-ray demonstrating correction of the deformity (lordosis angle was $40^{\circ}$ ). $\mathbf{f} C T$ images showing satisfactory bone fusion at 9 months. $\mathbf{g}$, $\mathbf{h}$ X-ray images displaying good internal fixation position and solid bone fusion, with no loss of lordosis angle and no change in adjacent segment $\mathrm{DH}$ throughout 66 months of follow-up 

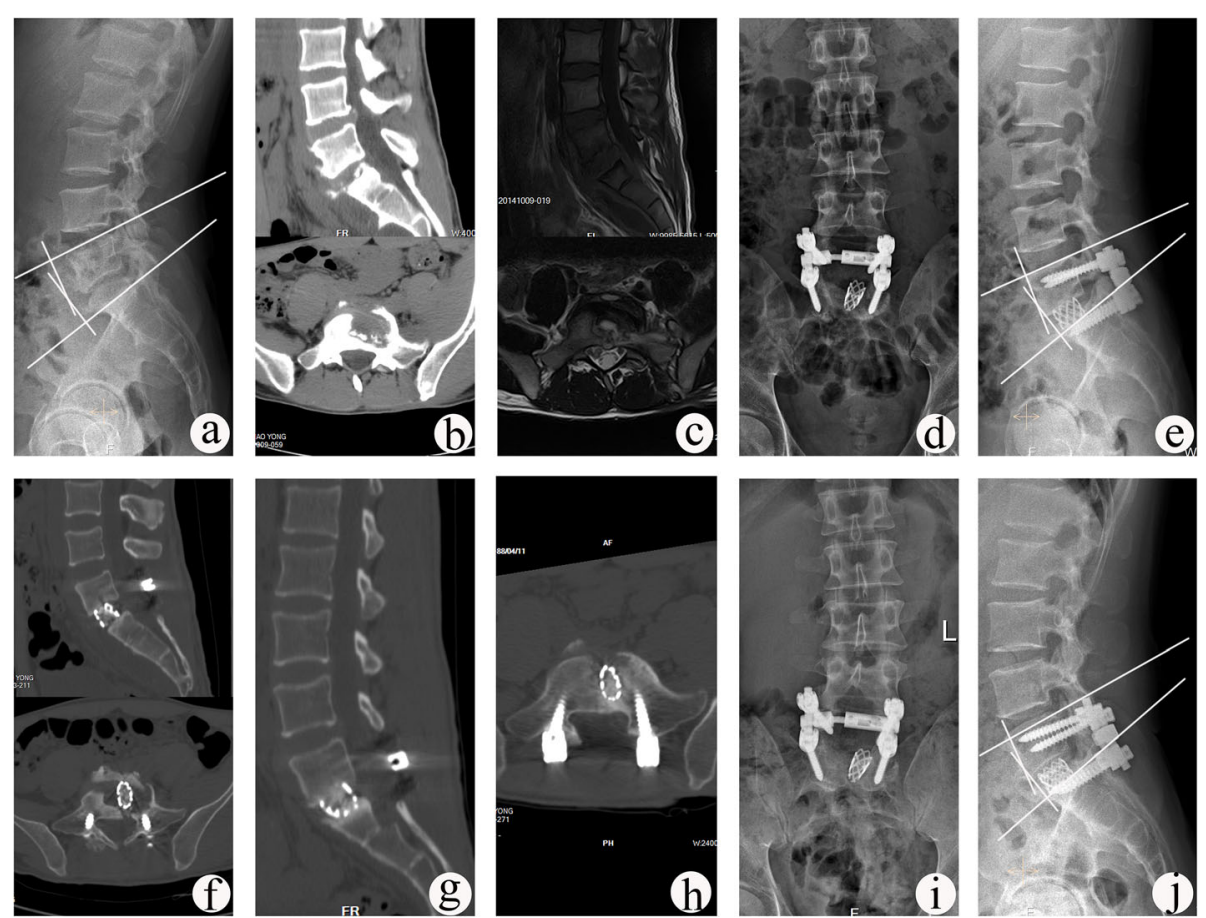

Fig. 2 A 26-year-old male with L5-S1 TB underwent one-stage posterior debridement, titanium mesh cage bone grafting and single-segment fixation. a-c Preoperative images show lesions with lumbosacral angle of $12^{\circ}$ and upper DH of $10.7 \mathrm{~mm}$. $\mathbf{d}$-f Postoperative X-ray demonstrating correction of the deformity (lumbosacral angle was $18^{\circ}$ ) and C $T$ findings showing that the titanium mesh cage with autogenous bone particles was implanted into vertebral body. $\mathbf{g}, \mathbf{h}$ CT images showing satisfactory bone fusion at 12 months after surgery. $\mathbf{i}$, j X-ray displaying good internal fixation position and solid bone fusion, with the lumbosacral angle of $17^{\circ}$ and the upper $\mathrm{DH}$ of $10.5 \mathrm{~mm}$ at the follow-up period of $81 \mathrm{months}$

analysis [27]. These results suggest that mono-segment fixation can maintain the normal motion units and to some extent, retard the degeneration of adjacent segment.

Intervertebral bone grafting is critical for maintaining long-term stability of the spine after surgery according to the three columns theory of Denis [28]. Adopting posterior single-segment fixation limited exposure space, which is not suitable for large area bone grafting. One or two shaped titanium mesh cages filled with autogenous bone particles autogenous bone particles from healthy lamina and spinous process were implanted to reconstruct the anterior and middle column. This intervertebral bone grafting method by implanting ideal titanium cage increases the contact area between the bone particles and the bone grafting surface, thus facilitating the penetration of various cytokines to promote bone metabolism and accelerate the osteogenesis. Furthermore, titanium mesh cage has the characteristics of high strength, strong support, and great friction on the contact surface, which can withstand compressive force well to prevent the bone from fracture and displacement. Furthermore, according to the specific shape of the bone defect between vertebrae, the titanium mesh can be trimmed and shaped to match the shape of the bone defect. Thus, more healthy bone can be retained, thus avoiding the decrease in spinal stability due to larger bone defects after the removal of the lesions [29]. Biomechanical studies have indicated that TB bacilli adhere weakly to the titanium materials and do not affect the bactericidal effect of anti-TB drugs [30]. In this study, we found that bone graft fusion was achieved in all patients. No deep infection, internal fixation loosening, fracture, and pseudoarticular formation occurred.

The advantages of one-stage posterior debridement, titanium mesh cage bone grafting, and single-segment fixation in the treatment of mono-segmental lumbar and lumbosacral spinal TB include as follows: (1) Removal of lesions and internal intervertebral bone fusion and instruments are achieved simultaneously through one incision, thus reducing surgical trauma and the risk of damage to vital organs; (2) Single-segment fixation preserves the normal motion of the lumbar regions, maintains spinal stability and slows down the degeneration of adjacent segments; (3) pedicle screws provides three-column fixation, and effectively restores the normal physiological curvature and height of the spine. The internal fixation is placed outside the focus to avoid infection; and (4) titanium mesh cage bone graft increases the contact area and the implant is not easy to remove, which is beneficial to bone cell metabolism and improves the bone graft fusion rate. 
Because there are the individual differences in lumbar and lumbosacral spinal TB, this surgical approach also has some limitations: (1) when the focus is concentrated in the anterior column or accompanied with huge abscess or flowing abscess, the anterior approach should be selected; (2) if multiple vertebral bodies are severely damaged, a combined anterior and posterior approach is required; (3) if the patients with severe osteoporosis or kyphosis, a long posterior segment fixation is needed to maintain its stability or correct the deformity. In addition, this study is a single-center study and the sample size is relatively small. In the future, prospective studies with larger samples are required to confirm the findings of this study.

\section{Conclusions}

One-stage posterior debridement, single-segment fixation, and titanium mesh cage interbody fusion represent effective and feasible treatment option for monosegmental lumbar and lumbosacral spinal tuberculosis in adults. This approach may preserve lumbar normal motor units and decrease ASD with the advantages of minimal invasiveness and rapid postoperative rehabilitation.

\section{Abbreviations}

ASD: Adjacent segment degeneration; CRP: C-reactive protein; CT: Computed tomography; DH: Disc height; ESR: Erythrocyte sedimentation rate; JOA: Japanese Orthopaedic Association; MRI: Magnetic resonance imaging; ODI: Oswestry Disability index; TB: Tuberculosis; UCLA: University of California at Los Angeles; VAS: Visual analog scale

\section{Acknowledgements}

Not applicable

\section{Authors' contributions}

Zhenchao Xu participated in the design of this study, performed statistical analysis, and drafted the manuscript. Xiyang Wang directed the study design and manuscript drafting. Zheng Liu collected the clinical data and follow-up details of the study and conducted the study. All authors read and approved the final manuscript.

\section{Funding}

This work was supported by the National Natural Science Foundation of China (No. 81672191). No benefit in any form has been or will be received from a commercial party related directly or indirectly to the subject of this manuscript.

\section{Availability of data and materials}

The datasets and materials generated or analyzed during the current study are available from the corresponding author on reasonable request.

\section{Ethics approval and consent to participate}

This study protocol was approved by the Ethics Committee of Xiangya Hospital, and the written informed consent was obtained from all patients.

\section{Consent for publication}

All patients signed informed consent forms to publish their personal details in this article.

\section{Competing interests}

The authors declare that they have no competing interests.
Received: 2 June 2020 Accepted: 6 October 2020

Published online: 14 October 2020

\section{References}

1. World Health Organization. Global tuberculosis report 2019. Geneva: World Health Organization; 2019.

2. Hassan K, Elmorshidy E. Anterior versus posterior approach in surgical treatment of tuberculous spondylodiscitis of thoracic and lumbar spine. Eur Spine J. 2016;25(4):1056-63.

3. Garcia-Rodriguez JF, Alvarez-Diaz H, Lorenzo-Garcia MV, Marino-Callejo A, Fernandez-Rial A, Sesma-Sanchez P. Extrapulmonary tuberculosis: epidemiology and risk factors. Enferm Infec Microbiol Clin. 2011;29(7):502-9.

4. Jain AK. Tuberculosis of the spine: a fresh look at an old disease. J Bone Jt Surg Br. 2010;92(7):905-13.

5. Moon MS, Moon YW, Moon JL, Kim SS, Sun DH. Conservative treatment of tuberculosis of the lumbar and lumbosacral spine. Clin Orthop Relat. 2002; 398:40-9.

6. Xu ZQ, Wang XY, Shen XJ, Luo CK, Wu P, Zeng H. One-stage lumbopelvic fixation in the treatment of lumbosacral junction tuberculosis. Eur Spine J. 2015:24(8):1800-5.

7. Liu Z, Zhang PH, Li WW, Xu ZC, Wang XY. Posterior-only vs. combined posterior-anterior approaches in treating lumbar and lumbosacral spinal tuberculosis: a retrospective study with minimum 7-year follow-up. J Orthop Surg Res. 2020;15(1):99.

8. Xu ZQ, Wang XY, Shen XJ, Luo CK, Zeng H, Zhang PH, Peng W. Posterior only versus combined posterior and anterior approaches for lower lumbar tuberculous spondylitis with neurological deficits in the aged. Spinal Cord. 2015:53(6):482-7.

9. Wang YX, Zhang HQ, Liao W, Tang MX, Guo CF, Deng A, Wu JH, Liu JY. Onestage posterior focus debridement, interbody graft using titanium mesh cages, posterior instrumentation and fusion in the surgical treatment of lumbosacral spinal tuberculosis in the aged. Int Orthop. 2016;40(6):1117-24.

10. Weinhoffer SL, Guyer RD, Herbert M, Griffith SL. Intradiscal pressure measurements above an instrumented fusion. A cadaveric study. Spine. 1995;20(5):526-31.

11. Bastian L, Lange U, Knop C, Tusch G, Blauth M. Evaluation of the mobility of adjacent segments after posterior thoracolumbar fixation: a biomechanical study. Eur Spine J. 2001;10(4):295-300.

12. Li ZW, Li ZQ, Tang BM, Ren R, Zhang Y, Li CL, Zhang XB. Efficacy of onestage posterior debridement and bone grafting with internal fixation in the treatment of monosegmental thoracolumbar tuberculosis. World Neurosurg. 2019;121:E843-51.

13. Ghiselli G, Wang JC, Hsu WK, Hsu WK, Dawson EG. L5-S1 Segment Survivorship and Clinical Outcome Analysis After L4-L5 Isolated Fusion. Spine. 2003;28(12):1275-80.

14. Lee CK, Vessa P, Lee JK. Chronic disabling low back pain syndrome caused by internal disc derangements. The results of disc excision and posterior lumbar interbody fusion. Spine. 1995:20(3):356-61.

15. Mori T, Leung CC. Tuberculosis in the global aging population. Infect Dis Clin North Am. 2010;24(3):751-68

16. Zeng $H$, Wang $X Y$, Zhang PH, Peng W, Liu Z, Zhang YP. Single-stage posterior transforaminal lumbar interbody fusion, debridement, limited decompression, three column reconstruction and posterior instrumentation in surgical treatment for single-segment lumbar spinal tuberculosis. Acta Orthop Traumatol Turc. 2015;49(5):513-21.

17. Hirakawa A, Miyamoto K, Masuda T, Fukuta S, Hosoe H, linuma N, Iwai C, Nishimoto H, Shimizu K. Surgical outcome of 2-stage (posterior and anterior) surgical treatment using spinal instrumentation for tuberculous spondylitis. J Spinal Disord Tech. 2010;23(2):133-8.

18. Jain AK, Dhammi IK, Prashad B, Sinha S, Mishra P. Simultaneous anterior decompression and posterior instrumentation of the tuberculous spine using an anterolateral extrapleural approach. J Bone Joint Surg Br. 2008;90(11):1477-81.

19. Benli IT, Kaya A, Acaroğlu E. Anterior instrumentation in tuberculous spondylitis: is it effective and safe? Clin Orthop Relat Res. 2007;460:108-16.

20. Wang $X Y$, Pang XY, Wu P, Luo CK, Shen XJ. One-stage anterior debridement, bone grafting and posterior instrumentation vs. single posterior debridement, bone grafting, and instrumentation for the treatment of thoracic and lumbar spinal tuberculosis. Eur Spine J. 2014;23(4):830-7.

21. Liang Q, Wang Q, Sun GW, Ma WX, Shi JD, Jin WD, Shi SY, Wang ZL. Fiveyear outcomes of posterior affected-vertebrae fixation in lumbar tuberculosis patients. J Orthop Surg Res. 2018;13(1):210. 
22. Du X, Ou YS, Zhu Y, Zhao ZH, Luo W, He B, Peng QQ, Hu JY. One stage posterior debridement, nonstructural bone graft in the surgical treatment of single segment thoracic tuberculosis: A retrospective single-center cohort study. Int J of Surg. 2019;65:134-9.

23. Defino HL, Scarparo P. Fractures of thoracolumbar spine: monosegmental fixation. Injury. 2005;36(Suppl 2):B90-7.

24. Wang ZL, Yuan HF, Geng GQ, Shi JD, Jin WD. Posterior mono-segmental fixation: combined with anterior debridement and strut graft, for treatment of the mono-segmental lumbar spine tuberculosis. Int Orthop. 2012;36(2):325-9.

25. Liu Z, Li WW, Xu ZC, Wang XY, Zeng H. One-stage posterior debridement, bone grafting fusion, and mono-segment vs. short-segment fixation for single-segment lumbar spinal tuberculosis: minimum 5-year follow-up outcomes. BMC Musculoskelet Disord. 2020;21(1):86.

26. Xu ZQ, Wang XY, Wu P, Pang XY, Luo CK, Zhang PH, Zeng H, Peng W. Surgical treatment for mono-segmental lumbar tuberculosis by single-stage posterior debridement, compact bone grafting and posterior singlesegment fixation. Injury. 2015:46(7):1311-6.

27. Xia XP, Chen HL, Cheng HB. Prevalence of adjacent segment degeneration after spine surgery. Spine. 2013;38(7):597-608.

28. Denis $F$. The three column spine and its significance in the classification of acute thoracolumbar spinal injuries. Spine. 1983;8(8):817-31.

29. Shen XJ, Liu HZ, Wang GP, Pang XY, Luo CK, Zeng H, Xu ZQ, Liu XY, Wang $X Y$. The role of single-stage posterior debridement, interbody fusion with titanium mesh cages and short-segment instrumentation in thoracic and lumbar spinal tuberculosis. J Neurosurg Sci. 2017;61(5):473-80.

30. Ha KY, Chung YG, Ryoo SJ. Adherence and biofilm formation of Staphylococcus epidermidis and mycobacterium tuberculosis on various spinal implants. Spine. 1999;30(1):38-43.

\section{Publisher's Note}

Springer Nature remains neutral with regard to jurisdictional claims in published maps and institutional affiliations.

Ready to submit your research? Choose BMC and benefit from:

- fast, convenient online submission

- thorough peer review by experienced researchers in your field

- rapid publication on acceptance

- support for research data, including large and complex data types

- gold Open Access which fosters wider collaboration and increased citations

- maximum visibility for your research: over $100 \mathrm{M}$ website views per year

At $\mathrm{BMC}$, research is always in progress.

Learn more biomedcentral.com/submissions 